\title{
Scaffolds in vascular regeneration: current status
}

This article was published in the following Dove Press journal:

Vascular Health and Risk Management

19 January 2015

Number of times this article has been viewed

\author{
Neelima Thottappillil \\ Prabha D Nair \\ Division of Tissue Engineering \\ and Regeneration Technologies, \\ Biomedical Technology Wing, Sree \\ Chitra Tirunal Institute for Medical \\ Sciences and Technology, Kerala, India
}

Correspondence: Prabha D Nair Division of Tissue Engineering and Regeneration Technologies, Biomedical Technology Wing, Sree Chitra Tirunal Institute for Medical Sciences and Technology, Poojapura, Kerala, 6950I2, India

Email pdnair49@gmail.com
Abstract: An ideal vascular substitute, especially in $<6 \mathrm{~mm}$ diameter applications, is a major clinical essentiality in blood vessel replacement surgery. Blood vessels are structurally complex and functionally dynamic tissue, with minimal regeneration potential. These have composite extracellular matrix (ECM) and arrangement. The interplay between ECM components and tissue specific cells gives blood vessels their specialized functional attributes. The core of vascular tissue engineering and regeneration relies on the challenges in creating vascular conduits that match native vessels and adequately regenerate in vivo. Out of numerous vascular regeneration concerns, the relevance of ECM emphasizes much attention toward appropriate choice of scaffold material and further scaffold development strategies. The review is intended to be focused on the various approaches of scaffold materials currently in use in vascular regeneration and current state of the art. Scaffold of choice in vascular tissue engineering ranges from natural to synthetic, decellularized, and even scaffold free approach. The applicability of tubular scaffold for in vivo vascular regeneration is under active investigation. A patent conduit with an ample endothelial luminal layer that can regenerate in vivo remains an unanswered query in the field of small diameter vascular tissue engineering. Besides, scaffolds developed for vascular regeneration, should aim at providing functional substitutes for use in a regenerative approach from the laboratory bench to patient bedside.

Keywords: scaffold, vascular regeneration, in vivo

\section{Introduction}

Blood vessels form compact closed circulatory circuits, with functions far more than conducting blood from heart to other tissues. The diverse function performed by blood vessels is facilitated by the presence of complex extracellular matrix (ECM) of blood vessels. The ECM of a blood vessel varies in its composition, thickness, and overall architecture ranging from arteries, capillaries to veins. ${ }^{1}$ Thus it poses a difficult task for drawing a line of symmetry in tissue engineering approach while choosing an appropriate scaffold material for tissue engineered vascular conduits. The lack of integrity in spatial and temporal level of ECM, makes it a challenging field of active investigation in tissue engineering perspectives. ECM functions include the maintenance of histological pattern of a blood vessel bearing the mechanical load imposed by moving blood. It acts as a scaffold providing major cues that direct vascular cell proliferation, migration, attachment, and proper physiological functions. It also sequesters growth factors and plays a role in growth, remodeling and regeneration of the blood vessel both through vasculogenesis and angiogenesis. The restoration of standard vascular function and structural integrity, with neovessel formation during vascular senescence 
and damage forms the basis of vascular regeneration. ${ }^{2}$ Tissue engineered vascular regeneration aims toward the development of vascular substitutes that can regenerate in vivo and function similar to a native vessel. ${ }^{3}$

Vascular diseases have taken the foremost position in death causing diseases in both developed and developing countries. ${ }^{4}$ Prevalence of cardiovascular disease is widespread. Atherosclerotic lesions in major blood vessels are a reason for increased morbidity and mortality. ${ }^{5}$ Along with coronary artery diseases, bypass grafts are in demand in replacement surgeries for peripheral arterial disease, end stage renal diseases, ${ }^{6}$ and pediatric congenital heart defects. ${ }^{7}$ The pathology of small and medium diameter blood vessels, and lack of suitable autologous substitutes (internal mammary artery, radial artery, saphenous vein) has increased the demand of a suitable tissue engineered vascular substitute that can mimic native blood vessels and remodel as required. The success of tissue engineering as a treatment modality in various other spheres has made it an attractive tool to depend on in cardiovascular disease therapy. Tissue engineering techniques rely on the principle of seeding and attachment of cells on scaffolds that are biomimetic. Thus it is evident that choice of a suitable scaffold is the prime objective in the tissue engineering approach.

A scaffold equivalent to native ECM, ECM of blood vessels is a much investigated area in the field of vascular tissue engineering. An ideal scaffold should reflect the biomechanical properties of blood vessels, while serving as a platform for cell attachment and proliferation..$^{8}$ It should be non-thrombogenic, non-immunogenic, biocompatible and hemocompatible, biodegradable with suitable pore size, elasticity etc, so that it finds its application from bench to bedside. The scaffold should thus facilitate the in vivo regeneration of a tissue engineered vascular construct when implanted at a suitable site.

This review focuses on the scaffold material and its properties that make them a suitable substitute for vascular regeneration. The recent advances and short comings of various scaffold materials chosen to aid vascular regeneration are also discussed. Various preclinical trials with scaffolds with or without cells have been devised in order to predict the success of scaffold material in animal models. These studies help to draw a functional extrapolation of the result obtained for further application in human subjects. Currently, large diameter synthetic substitutes are readily available with very minimal disadvantages, however, a conduit for small diameter $(<6 \mathrm{~mm})$ blood vessels still remains a "holy grail". Much of the work today is carried out for the creation of scaffold material that supports small diameter blood vessel replacement and the focus of the current article will revolve on this axis of relevance.

\section{ECM}

Large and medium sized vessels are composed of three distinct layers each with specific cell type and ECM that provides a blood vessel its functional architecture. The innermost layer, tunica intima, surrounds the lumen and consists of the endothelial cell lining with basement membrane and sub-endothelial connective tissue layer. This is followed by the middle layer, tunica media, in which vascular smooth muscle cells populate and is rich in ECM comprising of collagen-elastin-proteoglycans. Tunica adventitia is the outer most layer, where fibroblasts are embedded longitudinally, in collagen-elastin rich ECM and distinguished from outer medium by an external elastic lamina. The capillary network is devoid of this three layer pattern and comprises of endothelial cells resting on a basement membrane with sparsely distributed pericytes. The thickness of the vessel attributed by its cells and associated ECM varies with arteries and veins. Thus the structural dimension and composition of a native blood vessel is highly obscure making it a challenging candidate in the tissue engineering field. The ECM of blood vessels is generally known under terms like matrix or stroma. Table 1 represents major components of ECM of blood vessels. ${ }^{10}$

\section{Vascular scaffold}

There is a manifold increase in demand of implantable vascular grafts, especially small caliber vessels in cardiovascular

Table I Extracellular matrix components of blood vessels

\begin{tabular}{|c|c|c|c|c|c|c|}
\hline $\begin{array}{l}\text { Vessel type } \\
\text { (diameter) }\end{array}$ & $\begin{array}{l}\text { Elastic artery } \\
(30 \mathrm{~mm} \text { to } 5 \mathrm{~mm})\end{array}$ & $\begin{array}{l}\text { Muscular artery } \\
(6 \mathrm{~mm})\end{array}$ & $\begin{array}{l}\text { Vein } \\
(1-5 \mathrm{~mm})\end{array}$ & $\begin{array}{l}\text { Arteriole } \\
(>50 \mu \mathrm{m})\end{array}$ & $\begin{array}{l}\text { Veinule } \\
(20-100 \mu \mathrm{m})\end{array}$ & $\begin{array}{l}\text { Capillary } \\
(<20 \mu \mathrm{m})\end{array}$ \\
\hline $\begin{array}{l}\text { ECM } \\
\text { components }\end{array}$ & $\begin{array}{l}\text { Elastin, } \\
\text { fibronectin, fibrillin, } \\
\text { fibulin, collagen type I, } \\
\text { II, III, IV, V, VI, } \\
\text { proteoglycans }\end{array}$ & $\begin{array}{l}\text { Elastin, } \\
\text { fibronectin, fibulin, } \\
\text { collagen type I, III, } \\
\text { IV, V,VI, } \\
\text { proteoglycans }\end{array}$ & $\begin{array}{l}\text { Elastin, } \\
\text { fibronectin, collagen type I, } \\
\text { II, III, IV, VI, XII, XIV } \\
\text { proteoglycans }\end{array}$ & $\begin{array}{l}\text { Elastin, collagen I, } \\
\text { III, fibrillin }\end{array}$ & $\begin{array}{l}\text { Laminin, collagen IV, } \\
\text { fibronectin }\end{array}$ & $\begin{array}{l}\text { Collagen IV, } \\
\text { laminin } \\
\text { fibronectin, } \\
\text { HSPG }\end{array}$ \\
\hline
\end{tabular}

Abbreviations: ECM, extracellular matrix; HSPG, heparan sulfate proteoglycan. 
bypass graft procedures. Lack of suitable donor vessel source and failure of synthetic prostheses is making tissue engineered vascular graft fabrication a flourishing area of research. Tissue engineering involves the incorporation of isolated cells or substitutes, delivery of biomechanical cues, and finally placing the cells on or within supporting structures or scaffolds. ${ }^{11}$ A scaffold plays an inevitable role in tissue regeneration and repair. The state of the art biomaterial development that mimics the ECM of blood vessels has constantly evolved in the past few years. A scaffold can be defined as a three dimensional platform required to perform actions ranging from cell-biomaterial interaction, cell adhesion to a controllable biodegradation rate that matches with tissue regeneration. ${ }^{12}$ Apart from this, the blood vessel scaffold requires adequate compliance with native vessels and unique ability to remodel in vivo. Although a large number of properties and parameters have to be considered for creation of vascular prosthesis, few characteristics are more relevant for its success. Favorable properties of a blood vessel scaffold include low-thrombogenicity and non-immunogenicity, non-destructive to blood cells and enzymes, should not alter plasma proteins or cause depletion of blood electrolytes, ability to remodel, and other technological advancement that shortens time and cost of implantable grafts making it more patient friendly. ${ }^{13}$ High patency and compliance, porosity and sterility, resistance for kinking, stretchable and circumferential strength to withstand arterial pressure with ease of handling, and suturability are other desirable features. Another aspect of scaffold material is its biodegradation profile. ${ }^{14}$ Ideally a functional tissue engineered vascular conduit with desired mechanical and biological characteristics necessitates complete degradation with cell arrangement and tissue remodeling. One of the important properties of vascular conduit, thromboresistance, is associated with intact endothelial cell lining in the scaffold lumen. This lining maintains vascular tone, leukocyte adhesion, and platelet activation. A large number of approaches have been utilized for the creation of active cells anchored on tubular scaffolds. Cell-scaffold interaction biology plays a crucial role in success of tissue engineered conduit creation. Vascular cells and ECM components have critical structurefunctional relationships that define a blood vessel. Vascular scaffold material selected should thus have adequate cell adhesion properties which help in circumferential attachment of smooth muscle cells and endothelial cells with mutual perpendicularity. Scaffold fabrication techniques may also play a crucial role in enhancing cell attachment. Table 2 gives a general idea of vascular scaffold fabrication techniques. ${ }^{15}$
Table 2 Major scaffold fabrication techniques for vascular regeneration

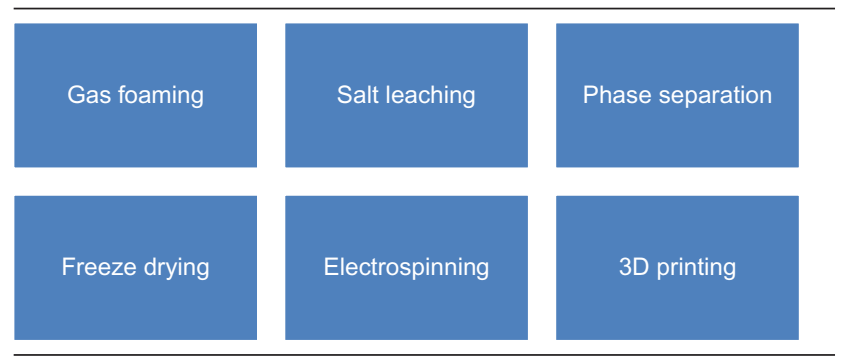

Note: Data from Rocco et al. ${ }^{15}$

\section{Polymeric scaffolds}

Polymers play a critical role in the tissue engineering technology acting as suitable scaffolds for vascular application mainly through versatility in chemical, mechanical, and biological properties of the polymeric materials. Characteristics of a polymer depend upon the chemical composition and structural orientation of its constituent molecules which in turn reflect its functional aspects. Selection of a suitable polymeric biomaterial for scaffolds depends on the end use. In the case of scaffolds for vascular conduit fabrication, the selected polymer should show all major properties right from cell adhesion to elastic distension. Polymeric material under consideration can be natural (biologic) or synthetic and even a blend. ${ }^{16}$ Initial vascular prostheses used non-degradable polymers like that of expanded polytetrafluoroethylene (ePTFE or Teflon) and Dacron (Polyethylene Terephthalate, PET). These substitutes dominated the clinical market of vascular substitutes for large diameter vessels, however, vascular regeneration was nil and lack of patency limits the use of these as small vessel substitutes and further regeneration. ${ }^{17}$ The electronegative luminal surface and porosity are the key features of Teflon. A 5 year patency of $91 \%$ to 95\% was achieved when used as arterial substitute with neither transanastomotic nor transmural endothelization of this graft. Decreased patency (45\%) is observed when it is used in femoropopliteal bypass surgery. This limits the use of ePTFE as a small diameter blood vessel substitute. Also, pertinent clinical data is lacking. ${ }^{18}$ Dacron is used as an aortic substitute, which also shows reduced patency in small diameter application. Premature atherosclerosis and $56 \%$ patency rate in femoral bypass in younger patients was observed. Dacron is flexible, elastic, and kink resistant. Platelet adhesion and leukocyte aggregation is more in the case of Dacron compared to ePTFE. Dacron was patented in 1950 and first implanted in 1957. To improve the patency of ePTFE, a procedure for autologous in vitro endothelization was attempted. After 9 days of in vitro culture, fibrin internally coated prosthesis seeded with endothelial cells was grafted as infrainguinal bypass in 310 patients. Fifteen years 
of clinical experience of endothelialized ePTFE prosthesis showed an appreciable patency rate similar to vein grafts. ${ }^{19}$ Applicability in regeneration of small caliber vessels has however not been convincing hence the research interest toward materials for vascular regeneration of small diameter vascular conduits.

The first endeavor in the creation of a tissue engineered blood vessel substitute was by Weinberg and Bell in 1986. ${ }^{20}$ Since then, strategies to create and enhance the properties of scaffold material selected in vascular conduit construction have been the prime theme of research. A wide range of materials ranging from natural to synthetic polymers, its blends, and decellularized tissue constructs have been subjected to research as a scaffold for small diameter blood vessel regeneration as detailed in the subsequent sections of the paper.

\section{Decellularized vascular scaffolds}

The increased understanding of the relevance of ECM on vascular tissue regeneration and its success in vivo has led to the use of alternative tissue sources as scaffold material. Decellularized allogeneic or xenogeneic tissues offer intact ECM with mechanical integrity and minimal inflammatory response elicitation. ${ }^{21-23}$ Decellularization is often achieved by processes like mechanical abrasions, enzymatic digestion, and chemical surfactant application. ${ }^{24}$ Additionally decellularized matrix offers advantages of three dimensional ultrastructural proteins and their functional properties. Such scaffolds show vascular regeneration ability with adequate cell attachment, proliferation, and migration. Porcine small intestinal sub mucosa and type I bovine collagen derived vascular constructs were interpositionally implanted in rabbit carotid artery for 90 days. ${ }^{25}$ Chemically decellularized porcine intestinal sub mucosa impregnated with bovine collagen was wrapped around a $4 \mathrm{~mm}$ mandrel. A rabbit model showed a high degree of patency without hyperplasia and aneurysm formation with infiltration of SMCs and ECs. The in vivo response of a decellularized aorta was also demonstrated by a trypsin based decellularization of porcine aorta; the decellularized aorta was seeded with human saphenous vein derived endothelial cells and myofibroblasts under bioreactor conditions and implanted subcutaneously in a rat model. It was observed that there was reduced presence of T-lymphocytes and leukocytes. ${ }^{26}$ Decellularized porcine iliac vessel seeded with endothelial progenitor cells, when implanted into the common carotid artery of a sheep by an end-to-end anastomosis showed patency for 130 days and demonstrated endothelial progenitor cells' contractile activity with nitric oxide mediated vasorelaxation very similar to native arteries. ${ }^{27}$ Detergent based decellularization of rat aorta and further coating with fibronectin accelerated luminal endothelization, good patency, and no thrombus formation. However, evidence suggests fibronectin induced localized myofibroblast hyperplasia. ${ }^{27} \mathrm{~A}$ recent attractive strategy employed showed improved biological in vivo results in vascular regeneration. The scheme included an indirect decellularization method of initially growing polyglycolide (PGA) tubular scaffolds with human allogeneic or canine SMCs under bioreactor conditions (7-10 weeks). This tubular cell seeded scaffold was decellularized and stored in a buffer at $4^{\circ} \mathrm{C}$. Canine cell base conduits constructed in this way showed long-term patency with no stenosis or dilation when implanted as canine coronary artery substitutes (12 months). Grafts demonstrated excellent patency and resisted dilatation, calcification, and intimal hyperplasia. Human engineered grafts were tested in a baboon model of arteriovenous access for hemodialysis. The baboon models (6 months) showed $88 \%$ patency. Such tissue-engineered vascular grafts could be extended to patients without suitable autologous tissue. ${ }^{28}$ Decellularized matrices in spite of advantages have been reported to show inflammatory responses and viral disease transmission probability. In addition, decellularized tissue source applicability is dependent on host age and health status of the animal, which in turn is reflected in the biomechanical properties of derived ECM. Further, the process of decellularization may remove desirable ECM components and thus affect its clinical performance. ${ }^{29-31}$ The biodegradation profile of decellularized scaffolds inadequately matchs the vascular regeneration process.

\section{Scaffolds from natural polymeric biomaterials}

Natural polymers from animal sources have more or less accurate optimization of ECM components and hence form a suitable choice as scaffold material. The scaffold fabricated from these naturally occurring polymers is mostly cell friendly and exceedingly biocompatible. Natural polymers generally do not activate chronic inflammation or toxicity to the host organism. ${ }^{32}$ However, the mechanical load bearing properties of these polymers and the biodegradation profile may not always be suitable. Major ECM components like that of collagen and elastin has been thoroughly investigated to date as scaffold material for vascular regeneration.

\section{Collagen}

Collagen is the most abundant ECM protein seen in our body and several collagen types have been identified. ${ }^{33}$ The excellent mechanical support provided by a collagen 
vascular structure makes it an inevitable scaffold material. Collagen scaffold based vascular tissue engineering possesses a long history and was first attempted by Weinberg and Bell in $1986 .{ }^{20}$ They used collagen and bovine aortic smooth muscle cells cast in an annular mold to obtain a tubular construct. The scaffold was highly distensible and pressure sensitive, rupturing at $10 \mathrm{~mm} \mathrm{Hg}$. Dacron mesh was later incorporated resulting in improved burst strength between 120 and $180 \mathrm{~mm} \mathrm{Hg}$. The reason for the enhanced burst pressure is due to circumferential orientation of collagen fibers. Longitudinal arrangement of SMCs was responsible for poor mechanical properties despite including the mesh. ${ }^{34}$

Collagen has a well-organized pattern in which vascular cells are dispersed and oriented in a blood vessel. The circumferential SMC orientation was achieved when human umbilical vein SMCs were seeded onto type III collagen gel around a mandrel. A layer of fibroblasts from human skin was seeded externally and endothelial cells were seeded inside. Three months of maturation showed a graft of enhanced mechanical properties. ${ }^{35}$ Collagen fibers have the ability to limit high strain deformation and thereby prevent the rupture of vascular walls. A cylindrical scaffold with SMCs seeded on it was made from rat tail tendon type I collagen. ${ }^{32}$ However, the scaffold showed reduced mechanical properties in terms of low stiffness and low elasticity, which makes it unsuitable for implantation. Cell-driven remodeling of the collagen matrix under dynamic conditioning has been shown to have potential in order to overcome this limitation. ${ }^{36}$ Cross-linking of collagen scaffolds by glycation or ultraviolet radiation improved their mechanical characteristics. ${ }^{37}$

Excellent mechanical properties and patency up to 6 weeks was observed in a collagen based construct of a low pressure loaded venous system. An arterial system was further developed by wrapping the construct with segmented, microporous polyurethane (PU) meshes later on. The most efficient cross-linking agent was glutaraldehyde; however cytotoxicity of this has led to alternatives. Other chemical cross-linkers like dimethyl suberimidate, dimethyl 3,3dithiobispropionimidate, and acyl azide. ${ }^{37}$ Enzymatic action of lysyl oxidase ${ }^{38}$ and transglutaminase ${ }^{39}$ has also been used for cross-linking. However collagen based scaffolds showed a stiffer, non-elastic nature. The degradation product of collagen results in production of amino acids that have thrombogenic potential and activates coagulation cascade. Besides, there is an enhanced risk of immunogenicity while using xenogeneic or allogeneic sources of material. The high cost of pure collagen also curtails its use as a cost effective approach to vascular graft construction.

\section{Elastin}

Elastin confers compliance to blood vessels. The walls of arteries are rich in elastin that stores elastic energy and high strain to ensure smooth blood flow. ${ }^{40}$ Scaffolds made of soluble elastin and collagen have porosity and surface area suitable for small diameter graft creation. Insoluble form of elastin has higher strain recovery than collagen. Addition of elastin to collagen gels enhanced the proliferative capacity of endothelial cells while significantly inhibiting SMC hyperplasia. ${ }^{41,42}$ Elastin containing scaffolds showed enhanced cell activity and elastic recoiling of collagen after strain effect. The tubular construct made from a mixture of elastin, GAGs, and type I collagen showed an inhibiting effect on proliferation of fibroblasts. Cross-linking with 1-ethyl-3-(3-dimethylaminopropyl) carbodiimide also improved the stability of elastin based scaffolds. ${ }^{43} \mathrm{~A}$ diepoxy cross linker, ethylene glycol diglycidyl ether made the elastin scaffold more brittle. Addition of elastin generally lowered the tensile strength and elastic modulus of scaffolds. ${ }^{43}$ From a microstructural point of view, elastin as a scaffold material showed solubilizing difficulty and inefficient mixing with other polymeric materials. The animal sourced elastin provided necessary biochemical cues to the scaffold but the potential immunogenicity resulted in aneurysmal graft failure. Human recombinant tropoelastin, when seeded with porcine bone marrow derived endothelial outgrowth cells, showed improved cell monolayer formation and appreciable mechanical properties. ${ }^{44}$

\section{Fibrin}

The prospective advantage of using fibrin scaffold as its source. Fibrin isolated from patients' own blood can be used to construct the scaffold. ${ }^{45,46}$ Therefore, the possibility of immune reaction is highly abridged. Several studies support the endothelial cell attachment on fibrin coated luminal surfaces of synthetic biomaterials to create hemocompatible grafts. Three dimensional cardiovascular fibrin scaffolds showed uniform cell layout and collagen deposition. Cells grown on fibrin scaffolds seem to produce ECM rich in collagen. The lack of adequate functional mechanical property requirement of scaffold was tackled with the addition of specific media factors, when human skin fibroblast grown in combination with TGF $\beta 1$, insulin and plasmin on fibrin scaffold showed increased tensile strength and collagen deposition. ${ }^{47}$ Tensile strength similar to rat abdominal aorta was achieved by proteinase inhibitor incorporated fibrin tubular construct for a 6 week culture. In vivo implantation in left jugular vein of lambs, with a $4 \mathrm{~mm}$ fibrin scaffold 
cultured with bovine SMCs and ECs in a rotating device for 3 to 10 days showed no aneurysm formation even after 5 weeks. After 15 weeks, in vivo patency was maintained at $71 \% .{ }^{48}$ Further histological analysis showed collagen and elastin deposition. Appreciable mechanical parameters have also been achieved. However, fibrin localization poses a problem of initiation of coagulation cascade and degradation profile of fibrin requires detailed investigation. ${ }^{49,50}$

\section{Hyaluronan (HA)}

Hyaluronic acid is a linear nonsulfated glycosaminoglycan made of glucuronic acid and $\mathrm{N}$-acetyl glucosamine. Porcine model implanted (5 months) with Hyaff-II, a hyaluronan based material sealed with fibrin glue showed graft occlusion at the end of 3 months. But the graft almost completely degraded with formation of neotissue with complete endothelium, organized collagen, and elastin..$^{51}$

\section{Chitosan}

Chitosan is a chitin derivative and it finds a wide variety of applications as scaffold in tissue engineering due to its low cost, ease of production, antimicrobial activity, and biocompatibility. ${ }^{52}$ The interaction of chitosan and vascular cells has been thoroughly investigated. ${ }^{53}$ Coronary arterial SMCs and ECs are shown to have high affinity to chitosan with decreased SMC proliferation. Also, chitosan loaded with cells has less immune response when implanted in rats. ${ }^{53}$ Chitosan has structural similarity to GAGs and comparable degradability. The poor mechanical property of chitosan based scaffolds is solved by blending it with synthetic polymers $^{54}$ and even with gelatin. ${ }^{55}$

\section{Silk fibroin}

Recently silk fibroin scaffolds have gained immense attraction in the field of vascular tissue engineering due to their unique properties like mechanical conformity, low adverse immune reaction, and compatible degradation rates. ${ }^{56}$ Silk fibroin is mainly obtained from Bombyx mori silk worm. Electrospun silk has mechanical properties very similar to native arteries with minimal thrombogenicity. The degradation rate is not effective in the case of long-term vascular conduit application demanding the need of synthetic polymer blending. Also, degradation varies with site of implantation and spun fiber size. Tensile strength reduction was also observed within a period from 6 weeks to 1 year of implantation. In certain cases it also elicited foreign body response after implantation. Gel spun silk fibroin when implanted in rat model resulted in occlusion despite of confluent endothelium formation. ${ }^{57}$

\section{Gelatin}

The potentiality of gelatin as a vascular scaffold material is under active investigation now. Due to similarities with collagen, its natural origin and low cost are the main driving factors that incline vascular tissue engineers toward the selection of this polymer. ${ }^{58}$ Moreover the immunogenicity offered by gelatin is very minimal and its degradability is appreciable. Gelatin is derived from collagen by denaturing the triple helical conformation. The main amino acid compositions are proline, glycine very similar to collagen.

The two types of gelatin are type A (acidic pre-treatment) and type B (alkaline pre-treatment). More carboxylic groups are present in type A gelatin than type B, making type much preferable for scaffold construction. Appreciable endothelial cell attachment has been observed on type B gelatin scaffolds. Gelatin solutions are electrospinnable and exhibit higher tensile strength $(8-12 \mathrm{Mpa})$ than collagen fibers. Elongation of $0.08-0.1 \mathrm{~mm} / \mathrm{mm}$ was also obtained. A major disadvantage of gelatin is its solubility; it dissolves as a colloidal sol at temperatures at or above $37^{\circ} \mathrm{C}$, and gels at lower temperatures around room temperature. This limits its long-term graft application.

Cross-linking of gelatin is necessary for its stability, which further prolongs its degradation time and enhances the water resistant nature of gelatin. ${ }^{59}$ For vascular tissue regeneration application, gelatin has been used as a coating agent to enhance cell attachment.

A recent study presented a successful attempt to obtain electrospun gelatin nanofibers cross-linked with a low-toxicity agent, genipin, which dramatically reduced the extensibility of the electrospun mats, which displayed further remarkable improvements in elastic modulus and breaking stress after successive cross-linking up to values of about 990 and 21 $\mathrm{MPa}$, respectively. ${ }^{59}$ The results of the preliminary in vitro tests carried out using vascular wall mesenchymal stem cells indicated good cell viability and adhesion to the gelatin scaffolds. However, long-term studies on cross-linked electrospun gelatin need to be considered in order to assess the actual efficacy as a material for blood vessel tissue engineering.

Our laboratory has been focusing on the use of a cost effective natural polymer scaffold based on gelatin which has been modified by copolymerization with vinyl acetate. Tubular scaffolds have been fabricated via processes of electrospinning to generate a fibrous and porous morphology which mimics the native ECM structure. The gelatin copolymer presented a favorable and natural cell responsive surface, which, under mechanical stimulation preferentially supported the contractile phenotype of smooth muscle cells. ${ }^{60}$ 


\section{Degradable synthetic polymers}

The inappropriate mechanical property limits the usage of natural polymers for vascular graft application. In the case of small diameter grafts the ability to withstand the physiological pressure without bursting is a necessity that most of the naturally derived scaffolds fail to meet. Thus it is quite reasonable to apply a synthetic macromolecule derived scaffold as most of its properties can be tailor made during its synthesis. The synthetic substitutes provide a platform for the longer term required for the construct to establish a cell layer. However, biological suitability of a selected synthetic conduit is still non-conclusive. There is evidence that degradative products of these polymers are shown to elicit inflammatory response. ${ }^{61}$ Even though, typical correlating data have not been derived, it has been well observed that degradation related inflammation is observed at the implantation site or in the lymphatic system. The long-term implantation of small diameter conduits thus requires a cooperative biological and mechanical performance for its applicability.

\section{PGA}

PGA formed through the ring opening polymerization of glycolide, is one of the first biodegradable polymers to be used for scaffold fabrication. ${ }^{62}$ It is a polyester which degrades via hydrolysis of ester bond, leaving behind glycolic acid which is further catabolized into water and carbon dioxide. The mechanical properties and degradation profile of PGA make it an attractive candidate for vascular tissue engineering. ${ }^{63}$ Implantation of PGA constructs seeded with ovine arterial cells in pulmonary arteries of lambs led to production of $73 \%$ collagen content after complete degradation of PGA within 11 weeks. ${ }^{64}$ Cells showed better proliferation ability on PGA and ECM secreted by the cells consisted of type I collagen and elastin. The dynamic culture conditioning of PGA scaffolds with $1 \mathrm{~Hz}$ and $7 \%$ strain led to an increase of tensile strength and modulus by a factor of nine.$^{65}$ The burst pressure was shown to increase to a value of $2,150 \pm 700 \mathrm{~mm}$ Hg for PGA-Dacron mesh scaffold when seeded with bovine SMCs and ECs and cultured for 8 weeks. However, SMCs showed an undifferentiated phenotype and elastin content was negligible. ${ }^{66}$ PGA tubular scaffolds modified with sodium hydroxide to improve hydrophilicity, and seeded with bovine aortic SMCs in pulsatile bioreactor niche, when interpositionally implanted into right saphenous artery of miniature swine model remained patent for 4 weeks. ${ }^{67}$ Electrospun PGA upon implantation into a rat resulted in fibrotic capsule formation at the implant interface after 7 days. This directly provides evidence for the inappropriate structural and chemical characteristics of scaffolds made of PGA alone, ${ }^{68}$ especially for long-term applications.

\section{Polylactide (PLA) and copolymers}

The ring open polymerisation of lactide results in polylactide which is a chiral molecule that exist in two forms D-PLA and L-PLA. It is a biodegradable thermoplastic polyester. Poly(Llactide) (PLLA) is a semicrystalline polymer $(\sim 37 \%)$ and Poly(DL-lactide) is an amorphous polymer, due to the random distribution of L- and D-lactide units. ${ }^{69}$ The hydrolytic product of PLLA is lactic acid which is further catabolized in the lactic acid cycle into water and carbon dioxide. ${ }^{70}$ Compared to PGA, the methylated PLA is more hydrophobic and thus degrades slowly. ${ }^{71}$ The copolymer poly(lactic-co-[glycolic acid]) (PLGA) made tubular construct showed appreciable SMC adherence and confluent EC luminal layer formation. The good tensile strength and limited deformation are highly attractive features of PLLA. But the modulus value of $5 \mathrm{GPa}$ is higher when compared to a native vessel. ${ }^{72}$ Surface modified PLLA with grafted fibronectin showed improved EC growth but lacked confluence. A 6 month evaluation of a PLGA-collagen scaffold seeded with SMCs and ECs implanted in canine pulmonary trunk showed no thrombus formation for 2 days. The histological analysis revealed an EC monolayer and parallel arrangement of SMCs after 2 months and finally adequate collagen and elastin matrix formation. ${ }^{73,74}$ Electrospun PLA showed less fibrotic reaction and less cellular infiltration but included the presence of giant cells. Dual layered electrospun PLGA seeded with vascular cells differentiated from dog bone marrow with internal diameter of $5 \mathrm{~mm}$, when implanted as an artery substitute for 3 weeks in an adult dog model, showed appreciable patency. In vivo implantation of porous film of PLGA showed cellular organization similar to a native vessel, ${ }^{72}$ however, the PLGA nanofibrous scaffold showed potential shrinkage in aqueous media due to polymer chain relaxation thus affecting cellular activity. PLGA scaffolds also showed a pre-degradation profile during sterilization. ${ }^{75}$ Electroactive PLA scaffolds offer a promising future application as this allows modulating scaffold and cellular behavior in accordance with electrical gradients, as in a bioreactor niche.

\section{Poly( $\varepsilon$-caprolactone) (PCL) and copolymers}

The ring opening polymerization of $\varepsilon$-caprolactone results in semicrystalline polyester PCL. It is a hydrophobic polymer with a melting point in the range of $54^{\circ} \mathrm{C}-60^{\circ} \mathrm{C}$, 
making the polymer easily formable at low temperature. ${ }^{76}$ PCL degrades slowly by hydrolysis of ester linkage and form $\varepsilon$-hydroxycaproic acid. The degradation products are ultimately removed by giant cells. The initial attempt was to make a PCL based veinal substitute. ${ }^{77,64}$ PCL elasticity closely matches native values and has a high extension rate before breakage, but tensile strength of PCL is less appreciable. ${ }^{78}$ An electrospun tubular PCL scaffold showed a burst pressure of 4,000 $\mathrm{mm} \mathrm{Hg}$, a value very close to natural tissue. ${ }^{79}$ PCL based small diameter vascular constructs have been reported to have good suture retention value and compliance to withstand physiological conditions of blood vessels ${ }^{80}$ The substrate morphology influenced cell activity in vascular tissue engineering is well demonstrated with layered PCL scaffolds. A $4.5 \mathrm{~mm}$ diameter PCL scaffold with different fiber orientation in each layer was electrospun by adjusting electrical and rotating collector parameters. The innermost layer of PCL nanofibers was aligned along the axial direction of the tubular scaffold and outer layer with circumferentially orientated fibers. This mimicked the layered arrangement of blood vessels and further supported endothelial cell attachment. ${ }^{81}$ The healing and degradation of small diameter PCL grafts (ID: $2 \mathrm{~mm}$ ) after implantation in the rat arterial circulation for up to 6 months, compared with conventional ePTFE vascular grafts, showed appreciable endothelization and homogeneous neointima formation, which gradually leveled off in the 18th week post-implantation. ${ }^{14}$ However, the major drawback of these PCL grafts was the presence of severe chondroid metaplasia in the neointima at 6,12 , and 18 weeks, replaced by calcifications at 24 weeks. The local hypoxia accompanied by acidic degradation products triggered some pathways for a local response and stimulated the expression of growth factors, such as transforming growth factor $\beta 1$, which led to chondroid metaplastic degeneration. Electrospun PCL with differential porosity in two layers (inner low porosity than outer), when implanted in a rat showed complete endothelization and perfect patency with no thrombosis. ${ }^{82}$ In another study, an electrospun PCL tubular scaffold implanted into rat proximal native artery showed very interesting results with a patent conduit with no aneurismal dilation and limited intimal hyperplasia. ${ }^{83}$

Pediatric cardiovascular reconstruction of low pressure (veinal) system was achieved by PCL copolymers. PCLPLA with a weight ratio of 1:1 seeded with vein cells and later on with bone marrow derived cells was used effectively to replace the peripheral pulmonary artery of a 4 year-old girl. ${ }^{84-86}$ Poly(lactide-co-caprolactone) (PLCL) showed very good SMC attachment ${ }^{87}$ and 1:1 poly(glycolide-cocaprolcatone) (PGCL) has high quasi-elastic recovery. ${ }^{88}$ PLCL scaffold porosity is precisely controllable. ${ }^{89}$ A PLCL scaffold seeded with descending rabbit aortic SMCs cultured in a bioreactor with parameters $130 \mathrm{~mL} / \mathrm{min}, 25 \mathrm{mmHg}, 1$ $\mathrm{Hz}, 5 \%$ radial distension, had increased collagen production and proliferative SMC layer formation. ${ }^{89}$ This scaffold was constructed by extrusion - leaching particulates technique. Lack of toxicity and attractive degradation profile of poly(Llactide-co- $\varepsilon$-caprolactone), P(LLA-CL) had driven further research toward the constructs from this copolymer. Human arterial smooth muscle cell seeded P(LLA-CL) scaffolds had longitudinal orientation and proliferation of these cells..$^{90,91}$ The mechanical properties of P(LLA-CL) electrospun tubes (ID: $2.3-2.5 \mathrm{~mm}$ ) indicated that the compliance was inversely related to the wall thickness, in the range $45-336 \mathrm{~mm}$. An increase in the wall thickness rapidly reduced the compliance, but the stiffness value of each electrospun P(LLA-CL) tube was still much smaller than that of the ePTFE graft. The P(LLA-CL) tube with a smaller wall thickness better simulated the mechanical properties of a native artery. Longterm viability (105 days) of porcine coronary artery SMCs cultured on an electrospun P(LLA-CL) nanofibrous scaffold showed that multiple cell layers were formed on the matrix after 2 months of culture, with ten fold ECM deposition after 3 months of culture compared with day 50 of culture. ${ }^{92}$ It was also observed that SMCs cultured on the scaffolds did not significantly increase the degradation rate of the scaffolds, and that the matrix still supported cell growth while degrading. However, the cell-scaffold constructs did not provide satisfactory mechanical strength and structural integrity. P(LLA-CL) nanofibers facilitated long-term (1-3 months) SMC growth compared to PGA and PLGA scaffolds, showing the lowest degradation rate. P(LLA-CL) nanofibers, as well as PLGA, showed a linear reduction of molecular weight during degradation, regardless of whether or not they were cultured with cells. The cell viability on P(LLA-CL) was higher than that on PLGA nanofibers and comparable with that on tissue culture polystyrene substrate after 40 days. The mechanical strength reduction of $\mathrm{P}(\mathrm{LLA}-\mathrm{CL})$ nanofibers with cell culture is greater than those without cells in the first 80 days. Similarly PGA or PLLA non-woven felts with PCL/PLA sealant solution implanted in mice for 6 weeks resulted in integrated vascular neotissue formation with no thrombotic complications. However, foreign body reaction with giant cell formation was observed ${ }^{93}$ In vivo pilot experimentation in a rabbit venous model of electrospun P(LLA-CL) (70:30) coated with collagen showed no thrombosis but lacked intact EC layer. ${ }^{94}$ 
Coaxial electrospun P(LLA-CL) with an unbound heparin core seeded with EC implanted into femoral arteries of dogs showed a patency rate of 25\% (1 month), $85 \%$ (3 months), and $75 \%$ (3 months) in three respective studies. ${ }^{95-97}$

\section{Polyhydroxyalkanoate (PHA) and copolymers}

PHA can be altered to show a wide range of mechanical properties and degradation rates. ${ }^{98} \mathrm{PHA}$ is a polyester produced by microbes like bacteria under nutrient limited conditions with excess carbon supply. ${ }^{99}$ PHA also shows good biocompatibility making it attractive for vascular conduit construction. It sustains cell attachment and proliferation, but was shown to generate prolonged acute inflammatory response. A $7 \mathrm{~mm}$ long PHA-PGA tubular scaffold seeded with ovine carotid artery cells, implanted into a lamb aorta showed patency for 5 months and stress-strain behavior similar to a native vessel. ${ }^{100}$ A non-woven PGA mesh coated with $\mathrm{P} 4 \mathrm{HB}$ contained collagen type I and type II deposition. The construct was maintained under mechanical consideration in a bioreactor and achieved burst strength of $300 \mathrm{~mm} \mathrm{Hg}$ within 21 days. ${ }^{101,102}$ The effect of ascorbic acid signals when used along with basic fibroblast growth factor on a PGA/P4HB construct, stimulated cells to produce large quantities of collagen which in turn led to maturation of the vessel. ${ }^{103}$

\section{Polydiaxanone (PDS)}

The ring opening polymerization of $\mathrm{p}$-diaxanone produces PDS, a crystalline degradable polyester. It shows slower absorption rate, low inflammatory response, and higher flexibility and strength making it potent for scaffold applications. The degradation starts within 60 days and completes within 12 months. ${ }^{104}$ Rabbit aortic implantation with a PDS scaffold showed adequate endothelial cell lining. ${ }^{105}$ Modulus value of PDS has a customary range between maximum modulus of elastin and minimum modulus range of collagen. An electrospun PDS made small diameter vascular graft showed appreciable alignment of fibers, making it more cell-friendly. Accountable burst pressure and compliance was also obtained. ${ }^{80}$

\section{PU}

PU exhibits optimum tensile strength and high elasticity which makes it an appealing choice for construction of small diameter vascular conduits in particular. ${ }^{106} \mathrm{PU}$ is also biocompatible. Currently, the only PU graft available for clinical use in the USA is the Vectra graft (Thoratec Corp, Pleasanton, CA, USA), which has been approved by the
US Food and Drug Administration for hemodialysis access. Generally PU is considered non-degradable but it can undergo oxidative, hydrolytic and enzymatic degradation. ${ }^{107}$ Finer tensile strength and elastic property facilitates its usage as a vascular scaffold but it is shown to have less compliance and a biologically unstable nature. Reports suggest that tubular scaffolds of PU, aided endothelial cell attachment and showed significant cellular activity.

Electrospun polyester urethane urea (PEUU) seeded with SMCs showed a strong, flexible, anisotropic nature with tensile strength in the range of 2.0-6.5 $\mathrm{MPa}$ and strain at break of $850 \%-1,700 \%$. SMCs proliferate well and are distributed confluently. ${ }^{106}$ Non-degradable PU (Biomer) was initially implanted in canine carotid artery. ${ }^{108}$ Canine interpositionally carotid implants remained patent for 2 years using intra-operative heparin and pre- and postoperative anti-platelet drugs. ${ }^{109}$ Recently, results of a study indicated intravascular implant patency of 95\% when an electrospun PU scaffold (Pellathane) was implanted into the abdominal aorta of rats. Luminal surface was covered with intact endothelial cell lining and there was no evidence of neointima formation. ${ }^{110}$

Electrospun degradable PU grafts in rat abdominal aortas remained $40 \%$ patent over 8 weeks but a case of thrombosis was reported later. ${ }^{11}$ To eliminate thrombotic property, further coating or blending of PEUU was done with 2-methacryloyloxyethyl phosphorylcholine (MPC), a material known to reduce platelet adhesion. MPC copolymer 2-methacryloyloxyethyl phosphorylcholine-comethacryloyloxyethyl butyl urethane (PMBU) blended PEUU grafts implanted into rat abdominal aorta remained patent for 8 weeks $(67 \%){ }^{112}$

\section{Poly(glycolide-co-dioxanone-co- trimethylene carbonate)}

Biosyn is composed of $60 \%$ glycolide, $14 \%$ dioxanone, and $26 \%$ trimethylene carbonate. The center block is a random co-polymer of 1,3-dioxane-2-one (65 weight \%) and 1,4dioxane-2-one ( 35 weight $\%$ ). Biosyn has optimum soft tissue mechanical properties, biodegradability, and cytocompatibility to support vascular prosthesis creation. Tubular Biosyn scaffolds showed mechanical properties similar to those of collagen and elastin. ${ }^{13}$

\section{Poly(glycerol-sebacate) (PGS)}

Polycondensation of glycerol and sebacic acid forms the elastomeric PGS. PGS shows appreciable mechanical properties and biocompatibility and degrades within 2 months 
in vivo. ${ }^{114} \mathrm{~A}$ PGS porous tube with heparin coating which was further wrapped in an electrospun PCL layer showed remarkable properties like confluent endothelium and contractile SMC layer with expression of elastin, collagen, and GAG. This was implanted in rats for 3 months and no aneurysm or stenosis was observed. ${ }^{115}$ In vitro hemocompatibility evaluation of PGS based biphasic scaffolds were shown to be non-thrombogenic compared to synthetic grafts. ${ }^{116}$ Single layered three dimensional microfluidic PGS scaffolds also achieved biomimetic fluid properties. ${ }^{117}$

\section{Polymer blends and composites}

It is well-known that a single polymeric material cannot satisfy all the functional requirements of a scaffold for vascular tissue engineering. Synthetic materials often lack the cell friendly nature that natural polymers offer. Also, the mechanical concern presented by synthetic ones is minimal in natural materials. An ideal vascular conduit substituting scaffold must have compromising properties in-between that of synthetic to natural range. It should meet conditions and conformations of native vessels to ultimately meet success in clinical trials. As a solution to this problem, material scientists are shifting the single scaffold material concept to a blended scaffold concept, in which different polymer combinations are tried to obtain the desired characteristics. ${ }^{118}$ The properties like cell affinity, degradation profile, and mechanical parameters can easily be tuned into single scaffold, applying varied combinations of polymeric materials.

PCL has been blended with a wide range of synthetic and natural polymers to improve the cell compatibility of the hybrid graft. PCL-PHBV small diameter tubular conduit showed mechanical properties very similar to that of native vessels and supported endothelial cell lining in 7 days. Blending collagen, elastin, and several other bioresorbable polymers like PCL, PLCL, PLGA, and PLLA in varying ratios had dimensional stability, biocompatibility, and mechanical properties making it well-suited for in vivo applications.

Electrospinning in three layers each of PCL, elastin, and collagen type I had considerably good mechanical properties. ${ }^{19}$ Recombinant tropoelastin spun inside a PCL layer when implanted in a rabbit resulted in endothelial cell attachment and reduced platelet attachment. It also had mechanical properties similar to controls with no evidence of dilatation, anastomotic dehiscence or seroma. ${ }^{120}$ A blend of PLLA, PGA, and collagen type 1 cultured with human umbilical vein endothelial cells and implanted in a canine model showed $100 \%$ patency with complete endothelization. Adequate production of collagen and elastin by cells was also detected. ${ }^{121}$
A blend of collagen type I and PCL electrospun tubes when implanted in a sheep model showed platelet adhesion in an unseeded graft, while the same when implanted in a rabbit remained patent for 1 month with absence of inflammatory infiltrate. ${ }^{122,123}$ A PLDLA and fibrin-knitted tubular scaffold showed adequate vessel remodeling with no thrombus formation and confluent endothelial cell layer and other ECM components when implanted in sheep for 6 months. ${ }^{124}$

\section{Conclusion and future perspectives}

Globally cardiovascular diseases rank among the top causes of death. Thus, there is a steady increase in demand for vascular prosthesis for blood vessel replacement surgeries. Large diameter vessel substitutes made of Dacron and Teflon have been successfully employed by surgeons, however, failure of such synthetic prostheses in medium to small diameter $(<6 \mathrm{~mm})$ bypass application necessitates the attention toward tissue engineered vascular grafts. A functional tissue engineered conduit greatly depends on various factors like cell source, biological and mechanical cues, and majorly on the selection of a suitable scaffold material. A blood vessel being a dynamic tissue, relies much on highly oriented extracellular matrix. Scaffold architecture thus should mimic the native blood vessel ECM and should adequately allow vascular regeneration in vivo. Material scientists are investigating an enormous variety of polymeric biomaterials that could meet the ideal requirements. They range from naturally occurring polymer to synthetic ones and even decellularized scaffolds. A composite scaffold made of natural-synthetic polymer blend offers promising results. In spite of active research in this field, a firm conclusion regarding the suitability of a material is not yet established. A vascular graft that can resist thrombosis by forming a confluent luminal endothelium, with mechanically compliant nature and that can be effectively replaced by a neovessel in vivo is still a dream in the field of vascular tissue engineering. The critical challenges include the optimization of vessel material so that it can withstand systemic arterial pressure and have the capacity to remodel. The surface modification of the scaffold materials has shown improvement of many of the properties and it is an attractive area of research. The future of vascular regeneration relies on bringing all the aspects together on one platform to generate a highly patent graft with a reliable off-the-shelf period and with cost effectiveness. Pioneering research interests in above mentioned areas will definitely help to elucidate the true potential of tissue engineered small diameter vascular grafts and enable this technology to reach clinical application. 


\section{Disclosure}

The authors have no conflicts of interest to disclose.

\section{References}

1. Rhodes JM, Simons M. The extracellular matrix and blood vessel formation: not just a scaffold. J Cell Mol Med. 2007;11(2):176-205.

2. Leeper NJ, Hunter AL, Cooke JP. Stem Cell Therapy for Vascular Regeneration Adult, Embryonic, and Induced Pluripotent Stem Cells Circulation. 2010;122(5):517-526.

3. Swartz DD, Andreadis ST. Animal models for vascular tissue-engineering. Curr Opin Biotechnol. 2013;24(5):916-925.

4. World Health Organisation [homepage on the Internet]. Cardiovascular diseases (CVDs). WHO. Available from: http://www.who.int/mediacentre/ factsheets/fs317/en/. Accessed June 24, 2014.

5. Lloyd-Jones D, Adams RJ, Brown TM, et al. Executive summary: Heart Disease and Stroke Statistics - 2010 Update A Report From the American Heart Association. Circulation. 2010;121(7):948-954.

6. Collins AJ, Foley RN, Chavers B, et al. 'United States Renal Data System 2011 Annual Data Report: Atlas of chronic kidney disease and end-stage renal disease in the United States. Am J Kidney Dis. 2012; 59(1 Suppl 1):A7, e1-e420.

7. Shinoka T, Breuer C. Tissue-Engineered Blood Vessels in Pediatric Cardiac Surgery. Yale J Biol Med. 2008;81(4):161-166.

8. Zhang WJ, Liu W, Cui L, Cao Y. Tissue engineering of blood vessel. J Cell Mol Med. 2007;11(5):945-957.

9. Conte MS. The ideal small arterial substitute: a search for the Holy Grail? FASEB J. 1998;12(1):43-45.

10. Bou-Gharios G, Ponticos M, Rajkumar V, Abraham D. Extra-cellular matrix in vascular networks. Cell Prolif. 2004;37(3):207-220.

11. DiMuzio P, Tulenko T. Tissue engineering applications to vascular bypass graft development: The use of adipose-derived stem cells. J Vasc Surg. 2007;(45 Suppl A):A99-A103.

12. Lee SJ, Liu J, Oh SH, Soker S, Atala A, Yoo JJ. Development of a composite vascular scaffolding system that withstands physiological vascular conditions. Biomaterials. 2008;29(19):2891-2898.

13. Chan BP, Leong KW. Scaffolding in tissue engineering: general approaches and tissue-specific considerations. Eur Spine J. 2008;17(4):467-479.

14. Pektok E, Nottelet B, Tille JC, et al. Degradation and Healing Characteristics of Small-Diameter Poly( $\varepsilon$-Caprolactone) Vascular Grafts in the Rat Systemic Arterial. Circulation. 2008;118(24):2563-2570.

15. Rocco KA, Maxfield MW, Best CA, Dean EW, Breuer CK. In Vivo Applications of Electrospun Tissue-Engineered Vascular Grafts: A Review. Tissue Eng Part B Rev. Epub June 18, 2014.

16. Gosline J, Lillie M, Carrington E, Guerette P, Ortlepp C, Savage K. Elastic proteins: biological roles and mechanical properties. Philos Trans R Soc Lond B Biol Sci. 2002;357(1418):121-132.

17. Deutsch M, Meinhart J, Zilla P, et al. Long-term experience in autologous in vitro endothelialization of infrainguinal ePTFE grafts. $J$ Vasc Surg. 2009;49(2):352-362.

18. Sayers RD, Raptis S, Berce M, Miller JH. Long-term results of femorotibial bypass with vein or polytetrafluoroethylene. Br J Surg. 1998;85(7):934-938.

19. De Bakey ME, Jordan GL Jr, Abbott JP, Halpert B, O'neal RM. The fate of dacron vascular grafts. Arch Surg. 1964;89(5):755-782.

20. Weinberg CB, Bell E. A blood vessel model constructed from collagen and cultured vascular cells. Science. 1986;231(4736):397-400.

21. Song JJ, Ott HC. Organ engineering based on decellularized matrix scaffolds. Trends Mol Med. 2011;17(8):424-432.

22. Badylak SF, Freytes DO, Gilbert TW. Extracellular matrix as a biological scaffold material: Structure and function. Acta Biomater. 2009;5(1):1-13.

23. Piterina AV, Cloonan AJ, Meaney CL, et al. ECM-Based Materials in Cardiovascular Applications: Inherent Healing Potential and Augmentation of Native Regenerative Processes. Int J Mol Sci. 2009;10(10):4375-4417.
24. Rathore A, Cleary M, Naito Y, Rocco K, Breuer C. Development of tissue engineered vascular grafts and application of nanomedicine. Wiley Interdiscip Rev Nanomed Nanobiotechnol. 2012;4(3):257-272.

25. Huynh T, Abraham G, Murray J, Brockbank K, Hagen P-O, Sullivan S. Remodeling of an acellular collagen graft into a physiologically responsive neovessel. Nat Biotechnol. 1999;17(11):1083-1086.

26. Bader A, Steinhoff G, Strobl K, et al. Engineering of human vascular aortic tissue based on a xenogeneic starter matrix. Transplantation. 2000;170(1):7-14.

27. Assmann A, Delfs C, Munakata H, et al. Acceleration of autologous in vivo recellularization of decellularized aortic conduits by fibronectin surface coating. Biomaterials. 2013;34(25):6015-6026.

28. Dahl SL, Kypson AP, Lawson JH, et al. Readily Available TissueEngineered Vascular Grafts. Sci Transl Med. 2011;3(68):68ra9.

29. Mano JF, Silva GA, Azevedo HS, et al. Natural origin biodegradable systems in tissue engineering and regenerative medicine: present status and some moving trends. $J R$ Soc Interface. 2007;4(17):999-1030.

30. Gelse K, Pöschl E, Aigner T. Collagens - structure, function, and biosynthesis. Adv Drug Deliv Rev. 2003;55(12):1531-1546.

31. L'Heureux N, Germain L, Labbé R, Auger FA. In vitro construction of a human blood vessel from cultured vascular cells: a morphologic study. J Vasc Surg. 1993;17(3):499-509.

32. Boccafoschi F, Rajan N, Habermehl J, Mantovani D. Preparation and characterization of a scaffold for vascular tissue engineering by directassembling of collagen and cells in a cylindrical geometry. Macromol Biosci. 2007;7(5):719-726.

33. Hirai J, Matsuda T. Venous reconstruction using hybrid vascular tissue composed of vascular cells and collagen: Tissue regeneration process. Cell Transplant. 1996;5(1):93-105.

34. Amadori L, Rajan N, Vesentini S, Mantovani D. Atomic Force and Confocal Microscopic Studies of Collagen-Cell-Based Scaffolds for Vascular Tissue Engineering. Adv Mater Res. 2007;15-17:83-88.

35. Hirai J, Kanda K, Oka T, Mastuda T. Highly oriented, tubular hybrid vascular tissue for a low pressure circulatory system. ASAIO J. 1994;40(3):M383-M388.

36. Seliktar D, Black AR, Vito RP, Nerem RM. Dynamic Mechanical Conditioning of Collagen-Gel Blood Vessel Constructs Induces Remodeling in vitro. Ann Biomed Eng. 2000;28(4):351-362.

37. Charulatha V, Rajaram A. Influence of different crosslinking treatments on the physical properties of collagen membranes. Biomaterials. 2003;24(5):759-767.

38. Elbjeirami WM, Yonter EO, Starcher BC, West JL. Enhancing mechanical properties of tissue-engineered constructs via lysyl oxidase crosslinking activity. J Biomed Mater Res A. 2003;66(3):513-521.

39. Orban JM, Wilson LB, Kofroth JA, El-Kurdi MS, Maul TM, Vorp DA. Crosslinking of collagen gels by transglutaminase. J Biomed Mater Res A. 2004;68(4):756-762.

40. Rabaud M, Lefebvre F, Ducassou D. In vitro association of type III collagen with elastin and with its solubilized peptides. Biomaterials. 1991;12(3):313-319.

41. Ito S, Ishimaru S, Wilson SE. Inhibitory Effect of Type 1 Collagen Gel Containing $\alpha$-Elastin on Proliferation and Migration of Vascular Smooth Muscle and Endothelial Cells. Cardiovasc Surg. 1997;5(2):176-183.

42. Daamen WF, van Moerkerk HTB, Hafmans T, et al. Preparation and evaluation of molecularly-defined collagen-elastin-glycosaminoglycan scaffolds for tissue engineering. Biomaterials. 2003;24(22): 4001-4009.

43. Leach JB, Wolinsky JB, Stone PJ, Wong JY. Crosslinked $\alpha$-elastin biomaterials: towards a processable elastin mimetic scaffold. Acta Biomater. 2005;1(2):155-164.

44. McKenna KA, Hinds MT, Sarao RC, et al. Mechanical property characterization of electrospun recombinant human tropoelastin for vascular graft biomaterials. Acta Biomater. 2012;8(1):225-233.

45. Ye Q, Zünd G, Benedikt $\mathrm{P}$, et al. Fibrin gel as a three dimensional matrix in cardiovascular tissue engineering. Eur J Cardiothorac Surg. 2000;17(5):587-591. 
46. Jockenhoevel S, Zund G, Hoerstrup SP, et al. Fibrin gel-advantages of a new scaffold in cardiovascular tissue engineering. Eur J Cardiothorac Surg. 2001;19(4):424-430.

47. Neidert MR, Lee ES, Oegema TR, Tranquillo RT. Enhanced fibrin remodeling in vitro with TGF- $\beta 1$, insulin and plasmin for improved tissue-equivalents. Biomaterials. 2002;23(17):3717-3731.

48. Swartz DD, Russell JA, Andreadis ST. Engineering of fibrin-based functional and implantable small-diameter blood vessels. Am J Physiol Heart Circ Physiol. 2005;288(3):H1451-H1460.

49. Aper T, Schmidt A, Duchrow M, Bruch HP. Autologous Blood Vessels Engineered from Peripheral Blood Sample. Eur J Vasc Endovasc Surg. 2007;33(1):33-39.

50. Rowe SL, Lee S, Stegemann JP. Influence of thrombin concentration on the mechanical and morphological properties of cell-seeded fibrin hydrogels. Acta Biomater. 2007;3(1):59-67.

51. Zavan B, Vindigni V, Lepidi S, et al. Neoarteries grown in vivo using a tissue-engineered hyaluronan-based scaffold. FASEB $J$. 2008;22(8):2853-2861.

52. Huang Y, Onyeri S, Siewe M, Moshfeghian A, Madihally SV. In vitro characterization of chitosan-gelatin scaffolds for tissue engineering. Biomaterials. 2005;26(36):7616-7627.

53. Chupa JM, Foster AM, Sumner SR, Madihally SV, Matthew HWT. Vascular cell responses to polysaccharide materials: in vitro and in vivo evaluations. Biomaterials. 2000;21(22):2315-2322.

54. Zhang M, Li XH, Gong YD, Zhao NM, Zhang XF. Properties and biocompatibility of chitosan films modified by blending with PEG. Biomaterials. 2002;23(13):2641-2648.

55. Mao JS, Zhao LG, Yin YJ, Yao KD. Structure and properties of bilayer chitosan-gelatin scaffolds. Biomaterials. 2003;24(6):1067-1074.

56. Soffer L, Wang X, Zhang X, et al. Silk-based electrospun tubular scaffolds for tissue-engineered vascular grafts. J Biomater Sci Polym Ed. 2008;19(5):653-664.

57. Lovett M, Eng G, Kluge JA, Cannizzaro C, Vunjak-Novakovic G, Kaplan DL. Tubular silk scaffolds for small diameter vascular grafts. Organogenesis. 2010;6(4):217-224.

58. Sell SA, McClure MJ, Garg K, Wolfe PS, Bowlin GL. Electrospinning of collagen/biopolymers for regenerative medicine and cardiovascular tissue engineering. Adv Drug Deliv Rev. 2009;61(12):1007-1019.

59. Panzavolta S, Gioffrè M, Focarete ML, Gualandi C, Foroni L, Bigi A. Electrospun gelatin nanofibers: Optimization of genipin cross-linking to preserve fiber morphology after exposure to water. Acta Biomater. 2011;7(4):1702-1709.

60. Thomas LV, Nair PD. Influence of Mechanical Stimulation in the Development of a Medial Equivalent Tissue-Engineered Vascular Construct using a Gelatin-g-Vinyl Acetate Co-Polymer Scaffold. J Biomater Sci Polym Ed. 2012;23(16):2069-2087.

61. Hubbell JA. Biomaterials in Tissue Engineering. Nature Biotechnology. 1995;13(6):565-576.

62. Gilding DK, Reed AM. Biodegradable polymers for use in surgery - polyglycolic/poly(actic acid) homo- and copolymers: 1. Polymer. 1979;20(12):1459-1464.

63. Dong Y, Yong T, Liao S, Chan CK, Stevens MM, Ramakrishna S. Distinctive Degradation Behaviors of Electrospun Polyglycolide, Poly(dl-Lactide-co-Glycolide), and Poly(1-Lactide-co-e-Caprolactone) Nanofibers Cultured With/Without Porcine Smooth Muscle Cells. Tissue Eng Part A. 2010;16(1):283-298.

64. Shinoka T, Shum-Tim D, Ma PX, et al. Creation Of Viable Pulmonary Artery Autografts Through Tissue Engineering. J Thorac Cardiovasc Surg. 1998;115(3):536-545.

65. Kim BS, Nikolovski J, Bonadio J, Mooney DJ. Cyclic mechanical strain regulates the development of engineered smooth muscle tissue. Nat Biotechnol. 1999;17(10):979-983.

66. Niklason LE, Abbott W, Gao J, et al. Morphologic and mechanical characteristics of engineered bovine arteries. J Vasc Surg. 2001;33(3):628-638.

67. Niklason LE, Gao J, Abbott WM, et al. Functional Arteries Grown in Vitro. Science. 1999;284(5413):489-493.
68. Hajiali H, Shahgasempour S, Naimi-Jamal MR, Peirovi H. Electrospun PGA/gelatin nanofibrous scaffolds and their potential application in vascular tissue engineering. Int J Nanomedicine. 2011;6:2133-2141.

69. Edlund U, Albertsson AC. Degradable Polymer Microspheres for Controlled Drug Delivery. Degradable Aliphatic Polyesters. 2002;157:67-112.

70. Xue L, Greisler HP. Biomaterials in the development and future of vascular grafts. J Vasc Surg. 2003;37(2):472-480.

71. Kannan RY, Salacinski HJ, Butler PE, Hamilton G, Seifalian AM. Current status of prosthetic bypass grafts: A review. J Biomed Mater Res B Appl Biomater. 2005;74(1):570-581.

72. Mooney DJ, Organ G, Vacanti JP, Langer R. Design and fabrication of biodegradable polymer devices to engineer tubular tissues. Cell Transplant. 1994;3(2):203-210.

73. Iwai S, Sawa Y, Ichikawa H, et al. Biodegradable polymer with collagen microsponge serves as a new bioengineered cardiovascular prosthesis. J Thorac Cardiovasc Surg. 2004;128(3):472-479.

74. Kim MJ, Kim JH, Yi G, Lim SH, Hong YS, Chung DJ. In vitro and in vivo application of PLGA nanofiber for artificial blood vessel. Macromolecular Research. 2008;16(4):345-352.

75. Nottelet B, Pektok E, Mandracchia D, et al. Factorial design optimization and in vivo feasibility of poly( $\varepsilon$-caprolactone)-micro- and nanofiber-based small diameter vascular grafts. J Biomed Mater Res A. 2009;89(4):865-875.

76. Woodruff MA, Hutmacher DW. The return of a forgotten polymer Polycaprolactone in the 21st century. Progress in Polymer Science. 2010;35(10):1217-1256.

77. Watanabe M, Shin'oka T, Tohyama S, et al. Tissue-Engineered Vascular Autograft: Inferior Vena Cava Replacement in a Dog Model. Tissue Eng. 2001;7(4):429-439.

78. Nair LS, Laurencin CT. Biodegradable polymers as biomaterials. Prog Polym Sci. 2007;32(8-9):762-798.

79. Drilling S, Gaumer J, Lannutti J. Fabrication of burst pressure competent vascular grafts via electrospinning: Effects of microstructure. J Biomed Mater Res A. 2009;88(4):923-934.

80. McClure MJ, Sell SA, Ayres CE, Simpson DG, Bowlin GL. Electrospinning-aligned and random polydioxanone-polycaprolactonesilk fibroin-blended scaffolds: geometry for a vascular matrix. Biomed Mater. 2009;4(5):055010.

81. Wu H, Fan J, Chu CC, Wu J. Electrospinning of small diameter 3-D nanofibrous tubular scaffolds with controllable nanofiber orientations for vascular grafts. J Mater Sci Mater Med. 2010;21(12): $3207-3215$

82. De Valence S, Tille JC, Giliberto JP, et al. Advantages of bilayered vascular grafts for surgical applicability and tissue regeneration. Acta Biomater. 2012;8(11):3914-3920.

83. De Valence S, Tille JC, Mugnai D, et al. Long term performance of polycaprolactone vascular grafts in a rat abdominal aorta replacement model. Biomaterials. 2012;33(1):38-47.

84. Shin'oka T, Imai Y, Ikada Y. Transplantation of a Tissue-Engineered Pulmonary Artery. N Engl J Med. 2001;344(7):532-533.

85. Matsumura G, Miyagawa-Tomita S, Shin'oka T, Ikada Y, Kurosawa H. First Evidence That Bone Marrow Cells Contribute to the Construction of Tissue-Engineered Vascular Autografts In Vivo. Circulation. 2003;108(14):1729-1734

86. Shin'oka T, Matsumura G, Hibino N, et al. Midterm clinical result of tissue-engineered vascular autografts seeded with autologous bone marrow cells. J Thorac Cardiovasc Surg. 2005;129(6):1330-1338.

87. Jeong SI, Kim BS, Kang SW, et al. In vivo biocompatibilty and degradation behavior of elastic poly(l-lactide-co- $\varepsilon$-caprolactone) scaffolds. Biomaterials. 2004;25(28):5939-5946.

88. Lee SH, Kim BS, Kim SH, et al. Elastic biodegradable poly(glycolideco-caprolactone) scaffold for tissue engineering. J Biomed Mater Res A. 2003;66(1):29-37.

89. Jeong SI, Kwon JH, Lim JI, et al. Mechano-active tissue engineering of vascular smooth muscle using pulsatile perfusion bioreactors and elastic PLCL scaffolds. Biomaterials. 2005;26(12):1405-1411. 
90. Xu C, Inai R, Kotaki M, Ramakrishna S. Electrospun Nanofiber Fabrication as Synthetic Extracellular Matrix and Its Potential for Vascular Tissue Engineering. Tissue Eng. 2004;10(7-8):1160-1168.

91. Xu CY, Inai R, Kotaki M, Ramakrishna S. Aligned biodegradable nanofibrous structure: a potential scaffold for blood vessel engineering. Biomaterials. 2004;25(5):877-886.

92. Dong Y, Yong T, Liao S, Chan CK, Ramakrishna S. Long-term viability of coronary artery smooth muscle cells on poly(1-lactide-co- $\epsilon$ caprolactone) nanofibrous scaffold indicates its potential for blood vessel tissue engineering. $J R$ Soc Interface. 2008;5(26):1109-1118.

93. Roh JD, Nelson GN, Brennan MP, et al. Small-diameter biodegradable scaffolds for functional vascular tissue engineering in the mouse model. Biomaterials. 2008;29(10):1454-1463.

94. Mo XM, Xu CY, Kotaki M, Ramakrishna S. Electrospun P(LLA-CL) nanofiber: a biomimetic extracellular matrix for smooth muscle cell and endothelial cell proliferation. Biomaterials. 2004;25(10):1883-1890.

95. Zhai W, Qiu L, Mo X, et al. Coaxial electrospinning of P(LLA-CL)/ heparin biodegradable polymer nanofibers: potential vascular graft for substitution of femoral artery. J Biomed Mater Res B Appl Biomater. 2013;102(1):1-8.

96. Wang S, Mo XM, Jiang BJ, et al. Fabrication of small-diameter vascular scaffolds by heparin-bonded P(LLA-CL) composite nanofibers to improve graft patency. Int J Nanomedicine. 2013;8:2131-2139.

97. Huang C, Wang S, Qiu L, Ke Q, Zhai W, Mo X. Heparin Loading and Pre-endothelialization in Enhancing the Patency Rate of Electrospun Small-Diameter Vascular Grafts in a Canine Model. ACS Appl Mater Interfaces. 2013;5(6):2220-2226.

98. Williams SF, Martin DP, Horowitz DM, Peoples OP. PHA applications: addressing the price performance issue: I. Tissue engineering. Int $J$ Biol Macromol. 1999;25(1-3):111-121.

99. Zinn M, Witholt B, Egli T. Occurrence, synthesis and medical application of bacterial polyhydroxyalkanoate. Adv Drug Deliv Rev. 2001;53(1):5-21

100. Shum-Tim D, Stock U, Hrkach J, et al. Tissue engineering of autologous aorta using a new biodegradable polymer. Ann Thorac Surg. 1999;68(6):2298-2304

101. Hoerstrup SP, Zünd G, Sodian R, Schnell AM, Grünenfelder J, Turina MI. Tissue engineering of small caliber vascular grafts. Eur $J$ Cardiothorac Surg. 2001;20(1):164-169.

102. Hoerstrup SP, Kadner A, Breymann C, et al. Living, autologous pulmonary artery conduits tissue engineered from human umbilical cord cells. Ann Thorac Surg. 2002;74(1):46-52.

103. Fu P, Sodian R, Luders C, et al. Effects of Basic Fibroblast Growth Factor and Transforming Growth Factor-beta on Maturation of Human Pediatric Aortic Cell Culture for Tissue Engineering of Cardiovascular Structures: ASAIO J. 2004;50(1):9-14.

104. Boland ED, Coleman BD, Barnes CP, Simpson DG, Wnek GE, Bowlin GL. Electrospinning polydioxanone for biomedical applications. Acta Biomater. 2005;1(1):115-123.

105. Greisler HP, Ellinger J, Schwarcz TH, Golan J, Raymond RM, Kim DU. Arterial regeneration over polydioxanone prostheses in the rabbit. Arch Surg. 1987;122(6):715-721

106. Grasl C, Bergmeister H, Stoiber M, Schima H, Weigel G. Electrospun polyurethane vascular grafts: In vitro mechanical behavior and endothelial adhesion molecule expression. J Biomed Mater Res A. 2010;93(2):716-723.

Vascular Health and Risk Management

\section{Publish your work in this journal}

Vascular Health and Risk Management is an international, peerreviewed journal of therapeutics and risk management, focusing on concise rapid reporting of clinical studies on the processes involved in the maintenance of vascular health; the monitoring, prevention and treatment of vascular disease and its sequelae; and the involvement of
107. Huang C, Chen R, Ke Q, Morsi Y, Zhang K, Mo X. Electrospun collagen-chitosan-TPU nanofibrous scaffolds for tissue engineered tubular grafts. Colloids Surf B Biointerfaces. 2011;82(2):307-315.

108. Boretos JW, Pierce WS. Segmented Polyurethane: A New Elastomer for Biomedical Applications. Science. 1967;158(3807):1481-1482.

109. Annis D. The development and the testing of a polyurethane (Biomer) arterial prosthesis. Bulletin of Materials Science. 1989;12(1):33-40.

110. Bergmeister H, Grasl C, Walter I, et al. Electrospun Small-Diameter Polyurethane Vascular Grafts: Ingrowth and Differentiation of Vascular-Specific Host Cells. Artif Organs. 2012;36(1):54-61.

111. Hong Y, Ye SH, Nieponice A, Soletti L, Vorp DA, Wagner WR. A small diameter, fibrous vascular conduit generated from a poly(ester urethane)urea and phospholipid polymer blend. Biomaterials. 2009;30(13):2457-2467.

112. Soletti L, Nieponice A, Hong Y, et al. In vivo performance of a phospholipid-coated bioerodable elastomeric graft for small-diameter vascular applications. J Biomed Mater Res A. 2011;96(2):436-448.

113. Thomas V, Donahoe T, Nyairo E, Dean DR, Vohra YK. Electrospinningof Biosyn $^{\circledR}$-based tubular conduits: Structural, morphological, and mechanical characterizations. Acta Biomater. 2011;7(5):2070-2079.

114. Hashi CK, Derugin N, Janairo RR, et al. Antithrombogenic Modification of Small-Diameter Microfibrous Vascular Grafts. Arterioscler Thromb Vasc Biol. 2010;30(8):1621-1627.

115. Zhao J, Qiu H, Chen D, Zhang W, Zhang D, Li M. Development of nanofibrous scaffolds for vascular tissue engineering. Int J Biol Macromol. 2013;56:106-113.

116. Motlagh D, Yang J, Lui KY, Webb AR, Ameer GA. Hemocompatibility evaluation of poly(glycerol-sebacate) in vitro for vascular tissue engineering. Biomaterials. 2006;27(24):4315-4324.

117. McClure MJ, Sell SA, Simpson DG, Bowlin GL. Electrospun Polydiaxanone, Elastin and Collagen Vascular Scaffolds: Uniaxial Cyclic Distension. Journal of Engineered Fibers and Fabrics. 2009;4(2):18-25.

118. Thomas V, Zhang X, Vohra YK. A biomimetic tubular scaffold with spatially designed nanofibers of protein/PDS ${ }^{\circledR}$ bio-blends. Biotechnol Bioeng. 2009;104(5):1025-1033.

119. McClure MJ, Sell SA, Simpson DG, Walpoth BH, Bowlin GL. A three-layered electrospun matrix to mimic native arterial architecture using polycaprolactone, elastin, and collagen: A preliminary study Acta Biomater. 2010;6(7):2422-2433.

120. Wise SG, Byrom MJ, Waterhouse A, Bannon PG, Weiss AS, Ng MK. A multilayered synthetic human elastin/polycaprolactone hybrid vascular graft with tailored mechanical properties. Acta Biomater. 2011;7(1):295-303.

121. Yokota $\mathrm{T}$, Ichikawa $\mathrm{H}$, Matsumiya $\mathrm{G}$, et al. In situ tissue regeneration using a novel tissue-engineered, small-caliber vascular graft without cell seeding. J Thorac Cardiovasc Surg. 2008;136(4):900-907.

122. Tillman BW, Yazdani SK, Lee SJ, Geary RL, Atala A, Yoo JJ. The in vivo stability of electrospun polycaprolactone-collagen scaffolds in vascular reconstruction. Biomaterials. 2009;30(4):583-588.

123. Enrico Ercolani, Costantino Del Gaudio, Alessandra Bianco. Vascular tissue engineering of small-diameter blood vessels: reviewing the electrospinning approach. Journal of tissue engineering and regenerative medicine.2013; 10.1002/term.1697.

124. Koch S, Flanagan TC, Sachweh JS, et al. Fibrin-polylactide-based tissue-engineered vascular graft in the arterial circulation. Biomaterials. 2010;31(17):4731-4739. 